\title{
A Uniform Benchmark for Testing SsrA-Derived Degrons in the Escherichia coli ClpXP Degradation Pathway
}

\author{
Maria Magdalena Klimecka, Anna Antosiewicz (D), Matylda Anna Izert (D), Patrycja Emanuela Szybowska, \\ Piotr Krzysztof Twardowski, Clara Delaunay and Maria Wiktoria Górna *
}

check for

updates

Citation: Klimecka, M.M.; Antosiewicz, A.; Izert, M.A.; Szybowska, P.E.; Twardowski, P.K.; Delaunay, C.; Górna, M.W. A Uniform Benchmark for Testing SsrA-Derived Degrons in the Escherichia coli ClpXP Degradation Pathway. Molecules 2021, 26, 5936. https://doi.org/10.3390/ molecules26195936

Academic Editors: Agata L. Starosta and Jean-Paul Armache

Received: 10 September 2021 Accepted: 24 September 2021 Published: 30 September 2021

Publisher's Note: MDPI stays neutral with regard to jurisdictional claims in published maps and institutional affiliations.

Copyright: (c) 2021 by the authors. Licensee MDPI, Basel, Switzerland. This article is an open access article distributed under the terms and conditions of the Creative Commons Attribution (CC BY) license (https:/ / creativecommons.org/licenses/by/ $4.0 /)$.
Structural Biology Group, Biological and Chemical Research Centre, Department of Chemistry, University of Warsaw, 00-927 Warsaw, Poland; mklimecka@chem.uw.edu.pl (M.M.K.); a.antosiewicz2@uw.edu.pl (A.A.); matylda.izert@uw.edu.pl (M.A.I.); p.szybowska@student.uw.edu.pl (P.E.S.); pk.twardowski@student.uw.edu.pl (P.K.T.); clara.delaunay07@gmail.com (C.D.)

* Correspondence: mw.gorna@uw.edu.pl

\begin{abstract}
The ssrA degron is commonly used in fusion proteins to control protein stability in bacteria or as an interaction module. These applications often rely on the modular activities of the ssrA tag in binding to the SspB adaptor and in engaging the ClpXP protease. However, a comparison of these activities for a substantial standard set of degron variants has not been conducted previously, which may hinder the development of new variants optimized exclusively for one application. Here, we strive to establish a benchmark that will facilitate the comparison of ssrA variants under uniform conditions. In our workflow, we included methods for expression and purification of ClpX, ClpP, SspB and eGFP-degrons, assays of ClpX ATPase activity, of eGFP-degron binding to SspB and for measuring eGFP-degron degradation in vitro and in vivo. Using uniform, precise and sensitive methods under the same conditions on a range of eGFP-degrons allowed us to determine subtle differences in their properties that can affect their potential applications. Our findings can serve as a reference and a resource for developing targeted protein degradation approaches.
\end{abstract}

Keywords: ClpXP; degradation; degron; protease; SspB; ssrA

\section{Introduction}

Protein degradation in living cells is indispensable for preserving homeostasis and is a crucial component of the regulatory, immune and stress response systems [1]. Removing aberrant or denatured proteins prevents the formation of toxic aggregates and allows recycling of amino acids [2]. On the other hand, specific regulation of protein half-lives can adapt cellular processes in response to the changing environment [3]. Bacteria have several pathways for specific protein degradation in which major proteolytic complexes are members of the ATPases Associated with diverse cellular Activities (AAA+) family [4,5]. A common element of protein degradation pathways is recognition of the target proteins by specific elements known as degrons [6]. Several proteases might recognize the same degrons [7-9] and further specificity can be conferred by the action of specialized adaptor proteins that cooperate with chosen substrate-protease pairs [10,11].

Modification of endogenous protein stability became a popular trend in protein research and drug discovery known as targeted protein degradation. Multiple protein degradation techniques were developed in eukaryotic cells including Proteolysis Targeting Chimeras (PROTACs), auxin-inducible degradation (AID), and hydrophobic tagging $[12,13]$. In bacteria, all directed protein degradation methods developed so far are based on the use of degrons [14]. Knowledge of degron properties, such as the strength of binding to the components of the degradation machinery or the impact on the efficiency of degradation is necessary for their informed use in fusion proteins.

One of the best described and most exploited bacterial degrons is the ssrA tag sequence $[14,15]$. In the bacterial quality control pathway, ssrA tag is added in a process 
called trans-translation. During trans-translation, tmRNA (transfer-messenger RNA) enters stalled ribosomes, replaces the mRNA and promotes the translation of a peptide tag (ssrA) onto the $\mathrm{C}$ terminus of the nascent polypeptide [16]. The ssrA tag is conserved across bacteria and in Escherichia coli is recognized mainly by the ClpXP protease, a member of the AAA+ family. To a lesser extent, also other AAA+ enzymes such as the ClpAP complex can degrade ssrA-tagged substrates $[7,17,18]$. ClpX is the unfoldase subunit comprising a hexameric ring decorated with dimers of the ClpX N-terminal Zinc Binding Domain (ZBD), while the peptidase $\mathrm{ClpP}$ forms a double ring of heptamers that can bind ClpX hexamers on one or both faces of the ClpP barrel (Figure 1a). The ssrA tag consists of 11 amino acids (AANDENYALAA) in which the AANDENY motif is responsible for binding of the ClpX adaptor, i.e., SspB protein, and the ALAA motif binds to the ClpX unfoldase central pore itself [19]. This modularity of ssrA is frequently exploited in biotechnology for diverse applications [15].

The biochemical parameters for various variants of the ssrA tag have already been described with the use of multiple experimental setups and methods [20-23]. However, typically only a few selected variants have been characterized per study, making it difficult to make proper variant comparison across studies due to different experimental conditions. Moreover, simultaneous evaluation of properties such as SspB binding and degradation efficiency is available only for a limited set of ssrA variants.

(a)

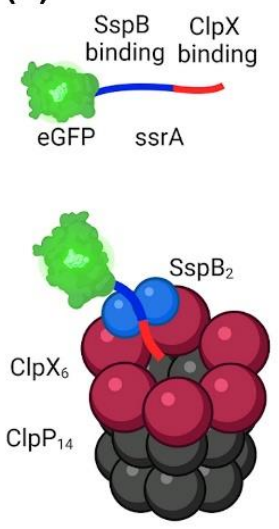

(b)

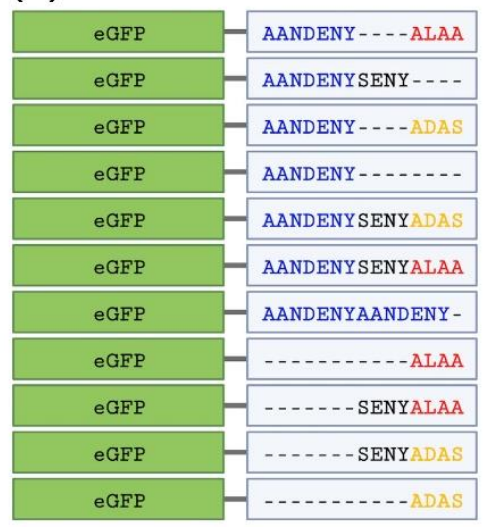

(c)

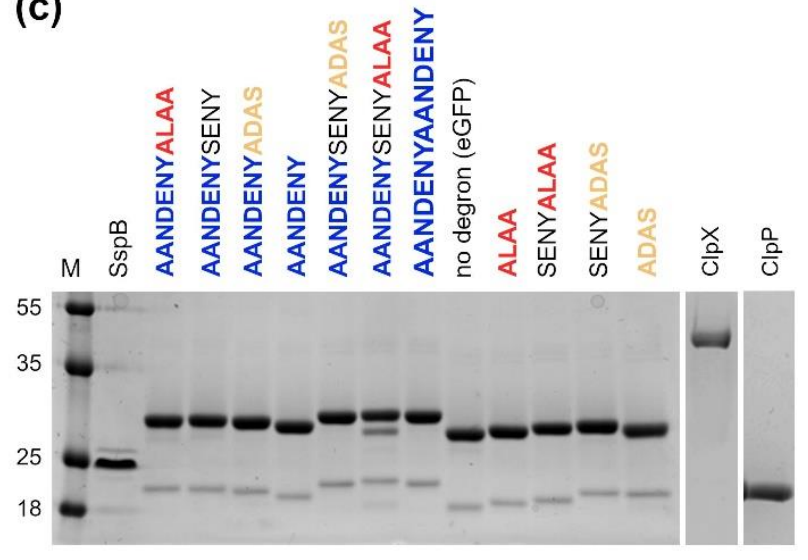

Figure 1. Characteristics of the studied proteins. (a) A schematic representation of the ClpXP protease machinery: the complex of the tetradecameric $\mathrm{ClpP}$ barrel-like structure $\left(\mathrm{ClpP}_{14}\right.$; gray) and the homohexameric $\mathrm{ClpX}$ ring $\left(\mathrm{ClpX}_{6}\right.$; purple), with an attached $\mathrm{SspB}$ dimer $\left(\mathrm{SspB}_{2}\right.$; blue) facilitating the eGFP-degron (green) binding to ClpX. The figure was created with BioRender.com and $\mathrm{Mol}^{*}$ [24]. (b) Fusions of the ssrA tag and its modified variants with eGFP protein used in the study. (c) SDS-PAGE protein electrophoresis profiles of SspB, eGFP- degrons, ClpX and ClpP proteins used in the study.

Herein, we strive to establish a benchmark that will facilitate the comparison of the ssrA degron and its variants under uniform conditions. We included methods for the expression and purification of the ClpX, ClpP, SspB, and eGFP-degron proteins (Figure 1b), as well as tests for the ATPase activity of ClpX, measurements of eGFP-degrons binding to the $\mathrm{SspB}$ protein and methods for measuring the degradation of eGFP-degrons in vitro and in vivo. Using uniform, precise and sensitive methods under the same conditions on a range of eGFP-degrons allowed us to determine subtle differences in their properties and to indicate their potential applications. Our findings can be a valuable point of reference and a resource for researchers using targeted protein degradation approaches.

\section{Results}

\subsection{Optimization of Protein Preparation for ClpX, ClpP, SspB and eGFP-Degron Constructs}

To be able to compare the efficiency of studied degrons in protein degradation in vitro, it was crucial to obtain a fully functional ClpX-ClpP-SspB complex. The first step to achieve 
this goal was to produce full-length recombinant proteins, especially ClpX together with its Zinc Binding Domain (ZBD) which interacts with SspB.

In order to obtain the highest possible consistency of results, all proteins of the ClpXClpP-SspB complex were cloned in our lab from the E. coli Top10 genome into a pET28a vector containing $\mathrm{N}$-terminal His-SUMO tags. After screening for the best overexpression conditions using E. coli BL21 (DE3), ClpP and SspB proteins were deemed sufficiently expressed after a few hours at $30^{\circ} \mathrm{C}$, while $\mathrm{ClpX}$ was expressed overnight at $18^{\circ} \mathrm{C}$. Substrate proteins comprising eGFP fused with a $C$-terminal ssrA-derived degron ("eGFP-degrons") and $\mathrm{N}$-terminal His-TEV purification tags were expressed from $\mathrm{pBAD}$ vectors to enable their controlled induction in E. coli BW25113 strain and its derivatives. ClpX, ClpP and SspB were purified by affinity chromatography (HisTrap column) followed by His-SUMO tag removal and size exclusion chromatography (Superdex200 column). eGFP-degrons were purified using the same columns in a tandem setup, without a His-TEV tag removal step. All proteins were purified with good efficiency. Although, after several attempts to optimize the protocols, significant degradation for ClpX and eGFP-degrons was still present (Supplementary Materials, Figure S1). To overcome this problem, His-SUMO-ClpX fusion was recloned into the $\mathrm{pBAD}$ enabling expression in the E. coli $\triangle$ clpP. For the same reason, eGFP-degron expression was also switched to the $\triangle c l p P$ strain. These changes in expression protocols resulted in good protein expression levels and a significant reduction in the observed degradation (Figure 1c).

\subsection{Validation of $Z B D$ and $C l p X$ Active Site Function by an ATPase Activity Assay}

To determine if the purified ClpX protein is active in vitro, ATP hydrolysis by ClpX was measured using an NADH-coupled assay (Figure 2). Several experimental conditions were evaluated: with increasing concentration of $\mathrm{SspB}$ or $\mathrm{ssrA}$, and alternatively with an increasing concentration of eGFP-ssrA at a constant concentration of $2.5 \mu \mathrm{M} \mathrm{SspB}_{2}$. ClpX was active and $\mathrm{SspB}$ alone increased reaction velocities up to roughly two-fold $(\mathrm{K}=0.22 \pm 0.03 \mu \mathrm{M}$ with a half-maximal value at $3.13 \mu \mathrm{M})$. The presence of the eGFP-ssrA substrate increased reaction velocities even further at larger eGFP-ssrA concentrations $(\mathrm{K}=0.50 \pm 0.01 \mu \mathrm{M}$ with a half-maximal value of $1.38 \mu \mathrm{M})$. Additionally, an expected increase in both the half-maximal value and reaction velocities was observed in the presence of both SspB and eGFP-ssrA ( $\mathrm{K}=0.20 \pm 0.03 \mu \mathrm{M}$ with a half-maximal value of $3.42 \mu \mathrm{M})$, indicating an interaction of SspB with the ZBD domain of ClpX.

\section{ClpX catalyzed ATP hydrolysis}

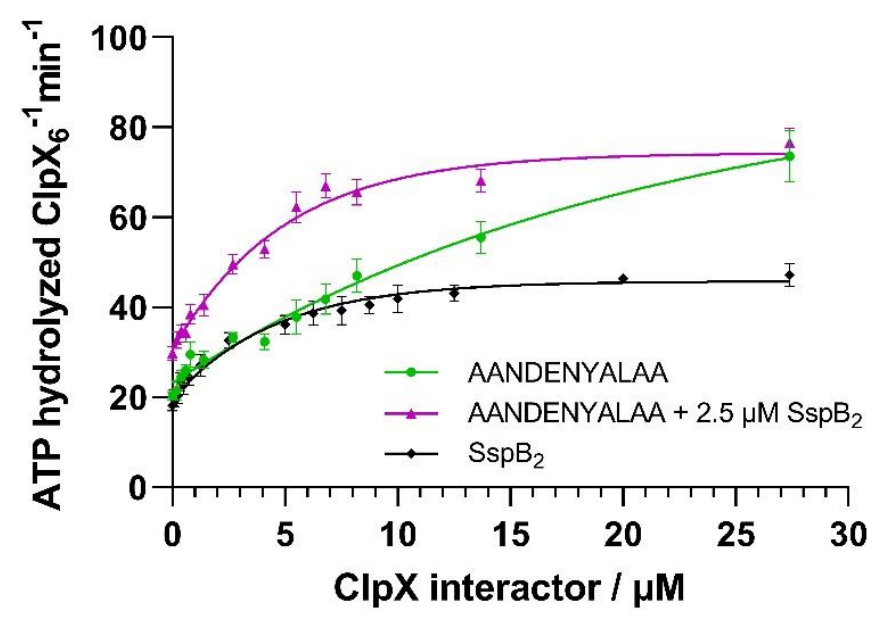

Figure 2. The in vitro assay of ClpX ATPase activity. ATP hydrolysis catalyzed by ClpX was measured using the NADH coupled assay by monitoring changes in NADH absorbance as a function of time in the presence of increasing concentrations of $\mathrm{SspB}_{2}$ (black curve) and increasing concentrations of eGFP-AANDENYALAA alone (green curve) or with the constant addition of $2.5 \mu \mathrm{M} \mathrm{SspB}$ (violet line). Data are presented as means with error bars as SEM for at least three technical replicates. 


\subsection{The Comparison of Binding of eGFP-ssrA Variants by $\operatorname{ssp} B$}

The next step was to check whether the purified SspB protein interacted in vitro with the individual ssrA variants. Native electrophoresis was used to visualize the interaction of various eGFP-degrons with $\mathrm{SspB}_{2}$. Two groups of degrons emerged (Figure $3 \mathrm{a}, \mathrm{b}$ ). The first group consisted of degrons that bound SspB due to the presence of the AANDENY sequence, and the second group comprised degrons that didn't bind SspB and were correspondingly lacking the AANDENY sequence. To quantify the differences in the binding efficiency of individual degrons to SspB, we determined their binding constants using microscale thermophoresis (MST) (Figure 3c,d and Supplementary Materials, Figure S2). MST confirmed that the AANDENY sequence is essential for degrons to bind to SspB, but also demonstrated that all degrons containing the AANDENY sequence bind with the efficacy comparable to WT ssrA $\left(K_{D}=0.08 \pm 0.02 \mu \mathrm{M}\right)$ ranging from $K_{D}=0.10 \pm 0.02 \mu \mathrm{M}$ for AANDENYSENY to $K_{D}=0.33 \pm 0.06 \mu \mathrm{M}$ for AANDENYADAS. The two degrons with the mutated "ADAS" C-terminal sequence replacing ALAA (AANDENYADAS; AANDENYSENYADAS: $\mathrm{K}_{\mathrm{D}}=0.30 \pm 0.08 \mu \mathrm{M}$ ) showed 2-3 fold higher dissociation constants. The binding of degrons lacking an AANDENY sequence was not detected under our experimental conditions.

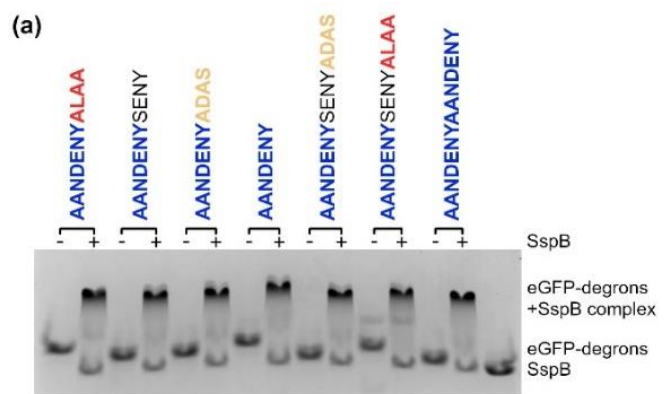

(b)

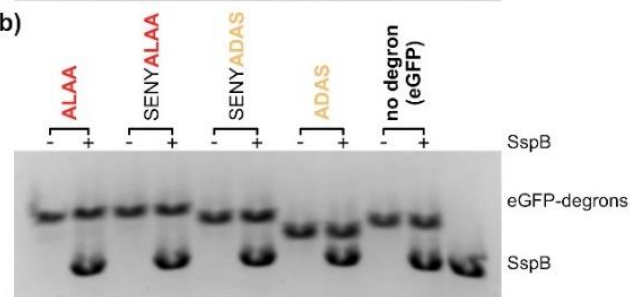

(c)

eGFP-degron binding to SspB

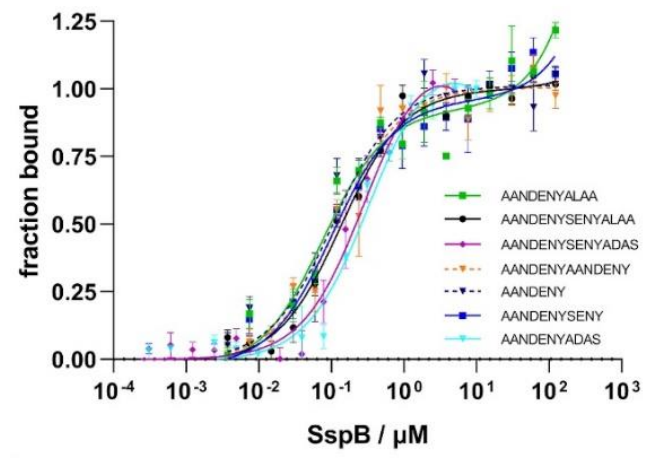

Figure 3. Cont. 


\begin{tabular}{|c|c|c|c|}
\hline \multirow{2}{*}{$\begin{array}{l}\text { (d) } \\
\text { eGFP-degron }\end{array}$} & \multicolumn{3}{|c|}{ binding with SspB } \\
\hline & $\begin{array}{l}K_{D} \\
\mu M\end{array}$ & $\begin{array}{c}\mathrm{K}_{\mathrm{A}} \\
\mu \mathrm{M}^{-1}\end{array}$ & $B_{\max }$ \\
\hline AANDENYALAA & $0.08 \pm 0.02$ & $13.19 \pm 0.33$ & $0.96 \pm 0.06$ \\
\hline AANDENYSENYALAA & $0.14 \pm 0.02$ & $7.80 \pm 1.00$ & $1.01 \pm 0.03$ \\
\hline AANDENYSENYADAS & $0.30 \pm 0.08$ & $3.37 \pm 0.64$ & $1.21 \pm 0.14$ \\
\hline AANDENYAANDENY & $0.12 \pm 0.03$ & $9.56 \pm 1.76$ & $1.01 \pm 0.05$ \\
\hline AANDENY & $0.11 \pm 0.02$ & $10.78 \pm 2.32$ & $1.02 \pm 0.05$ \\
\hline AANDENYSENY & $0.10 \pm 0.02$ & $9.78 \pm 0.61$ & $0.99 \pm 0.05$ \\
\hline AANDENYADAS & $0.33 \pm 0.06$ & $3.02 \pm 0.26$ & $1.18 \pm 0.07$ \\
\hline SENYALAA & $n b$ & $n b$ & $n b$ \\
\hline SENYADAS & $n b$ & $n b$ & $n b$ \\
\hline ALAA & $n b$ & $n b$ & $n b$ \\
\hline ADAS & $n b$ & $n b$ & $n b$ \\
\hline no degron & $n b$ & $n b$ & $n b$ \\
\hline
\end{tabular}

Figure 3. The in vitro study of SspB binding to eGFP-degron proteins. (a,b) Native electrophoresis revealed formation of complexes between $\mathrm{SspB}$ and eGFP proteins coupled with degrons containing the AANDENY motif (a), in contrast to no visible binding of SspB to eGFP proteins coupled with degrons lacking the AANDENY motif (b). (c) Confirmation of SspB binding to eGFP with degrons containing the AANDENY motif by MST). Data are presented as means with error bars as SEM for at least three technical replicates. (d) Quantification of the binding parameters $\left(\mathrm{K}_{\mathrm{D}}, \mathrm{K}_{\mathrm{A}}\right.$, and $\left.\mathrm{B}_{\max }\right)$ based on the analysis of MST data. nb—no detectable binding. Data are presented as mean \pm SEM.

\subsection{In Vitro Degradation of eGFP-Degrons by the ClpXP Complex}

Degradation of eGFP-degrons by the ClpXP complex (3:8 ratio of $\mathrm{ClpX}_{6}: \mathrm{ClpP}_{14}$ ) was measured as a decrease of eGFP fluorescence using a plate reader (Figure 4).

In the absence of $\mathrm{SspB}, \mathrm{K}_{\mathrm{M}}$ could be determined only for three degrons (AANDENYALAA: $\mathrm{K}_{\mathrm{M}}=3.38 \pm 0.39 \mu \mathrm{M}$; AANDENYSENYALAA: $\mathrm{K}_{\mathrm{M}}=1.55 \pm 0.20 \mu \mathrm{M}$; SENYALAA: $\left.\mathrm{K}_{\mathrm{M}}=4.31 \pm 0.69 \mu \mathrm{M}\right)$. This confirmed that the ALAA sequence was essential for degradation and the longer the sequence preceding it, the more efficient the degradation was. In the presence of SspB, 6 of the degrons had improved affinity $\mathrm{K}_{\mathrm{M}}$, up to by an order of magnitude for the WT ssrA sequence. The most efficient degradation was observed for degrons containing both the AANDENY and ALAA sequences (AANDENYALAA: $\mathrm{K}_{\mathrm{M}}=0.47 \pm 0.06 \mu \mathrm{M}$; AANDENYSENYALAA: $\left.\mathrm{K}_{\mathrm{M}}=0.48 \pm 0.05 \mu \mathrm{M}\right)$. There was no effect from the additional linker (SENY). The degron with an alternate "ADAS" C-terminal sequence (AANDENYSENYADAS: $\mathrm{K}_{\mathrm{M}}=0.79 \pm 0.16 \mu \mathrm{M}$ ) was less efficiently degraded, even more so for the sequence without the SENY linker (AANDENYDAS: $\mathrm{K}_{\mathrm{M}}=7.8 \pm 2.9 \mu \mathrm{M}$ ). Degrons containing the AANDENY sequence needed a longer C-terminal extension (AANDENYAANDENY: $\mathrm{K}_{\mathrm{M}}=1.41 \pm 0.28 \mu \mathrm{M}$; AANDENYADAS: $\mathrm{K}_{\mathrm{M}}=7.8 \pm 2.9 \mu \mathrm{M}$ ) to work efficiently. It was impossible to determine $K_{M}$ for the degron consisting only of the ALAA sequence unless it had a preceding linker (SENYALAA: $\mathrm{K}_{\mathrm{M}}=2.61 \pm 0.39 \mu \mathrm{M}$ ). For the rest of the tested degrons (AANDENY, AANDENYSENY, SENYADAS, ADAS) $K_{M}$ could not be determined due to a lack of sufficient degradation.

To confirm the stability of the ClpX-ClpP-SspB in vitro degradation was additionally analyzed using SDS-PAGE for the most efficient AANDENYALAA and AANDENYSENYALAA degrons. Substrate removal was faster for AANDENYSENYALAA ( 15 min to reach the steady-state level) in comparison with AANDENYALAA ( 60 min to reach the steady-state level) (Figure 5a,b). No additional degradation of SspB, ClpXP or the regeneration system components was observed after the degradation of eGFP-degrons, confirming specific substrate removal and stability of the applied assay. 
(a)

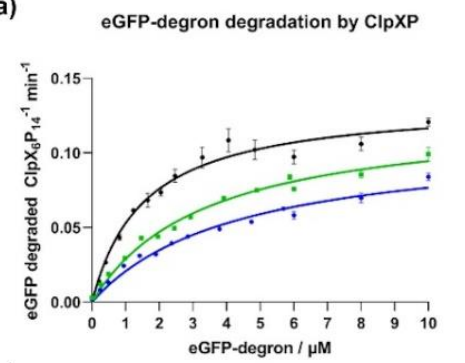

(c)

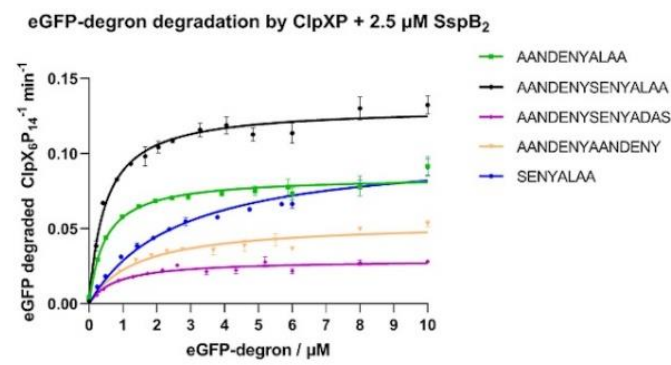

- aANDENYAlaA

- SenYalaA

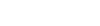

(b) eGFP-degron degradation by CIpXP

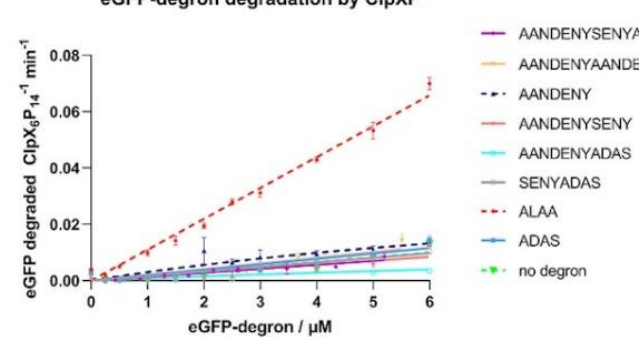

(d)

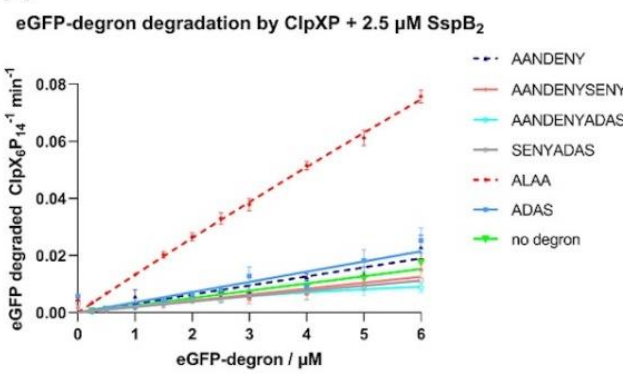

(e)

\begin{tabular}{|c|c|c|c|c|}
\hline \multirow[b]{2}{*}{ eGFP-degron } & \multicolumn{2}{|c|}{ without $S s p B_{2}$} & \multicolumn{2}{|c|}{ with $2.5 \mu \mathrm{M} \mathrm{SspB_{2 }}$} \\
\hline & $\begin{array}{l}\mathbf{K}_{\mathbf{M}} \\
\mu \mathrm{M}\end{array}$ & $\begin{array}{c}\mathbf{V}_{\max } \\
\mu \mathrm{M} \cdot \mathrm{min}^{-1}\end{array}$ & $\begin{array}{l}\mathbf{K}_{\mathbf{M}} \\
\mu \mathrm{M}\end{array}$ & $\begin{array}{c}\mathbf{V}_{\max } \\
\mu \mathrm{M} \cdot \mathrm{min}^{-1}\end{array}$ \\
\hline AANDENYALAA & $3.38 \pm 0.39$ & $0.126 \pm 0.006$ & $0.47 \pm 0.06$ & $0.085 \pm 0.002$ \\
\hline AANDENYSENYALAA & $1.55 \pm 0.20$ & $0.134 \pm 0.005$ & $0.48 \pm 0.05$ & $0.131 \pm 0.003$ \\
\hline AANDENYSENYADAS & nd & nd & $0.79 \pm 0.16$ & $0.029 \pm 0.001$ \\
\hline AANDENYAANDENY & nd & nd & $1.41 \pm 0.28$ & $0.054 \pm 0.003$ \\
\hline AANDENY & nd & nd & nd & nd \\
\hline AANDENYSENY & nd & nd & nd & nd \\
\hline AANDENYADAS & nd & nd & $7.8 \pm 2.9$ & $0.021 \pm 0.005$ \\
\hline SENYALAA & $4.31 \pm 0.69$ & $0.110 \pm 0.008$ & $2.61 \pm 0.39$ & $0.103 \pm 0.006$ \\
\hline SENYADAS & nd & nd & nd & nd \\
\hline ALAA & nd & nd & nd & nd \\
\hline ADAS & nd & nd & nd & nd \\
\hline no degron & nd & nd & nd & nd \\
\hline
\end{tabular}

Figure 4. In vitro degradation of eGFP-degron proteins by ClpXP. Evaluation through changes in the eGFP fluorescence in the absence $(\mathbf{a}, \mathbf{b})$ or presence of $2.5 \mu \mathrm{M} \mathrm{SspB} 2$ protein $(\mathbf{c}, \mathbf{d})$. Data are presented as means with error bars as SEM for at least three technical replicates. (e) The initial rate of protein degradation per $\mathrm{ClpX}_{6} \mathrm{P}_{14}$ unit at different eGFP-degrons concentrations was fit to the Michaelis-Menten plot allowing the determination of the process kinetic parameters $\left(\mathrm{K}_{\mathrm{M}}\right.$,

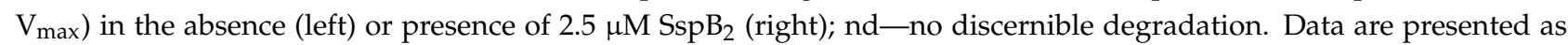
mean \pm SEM for at least three technical replicates. 

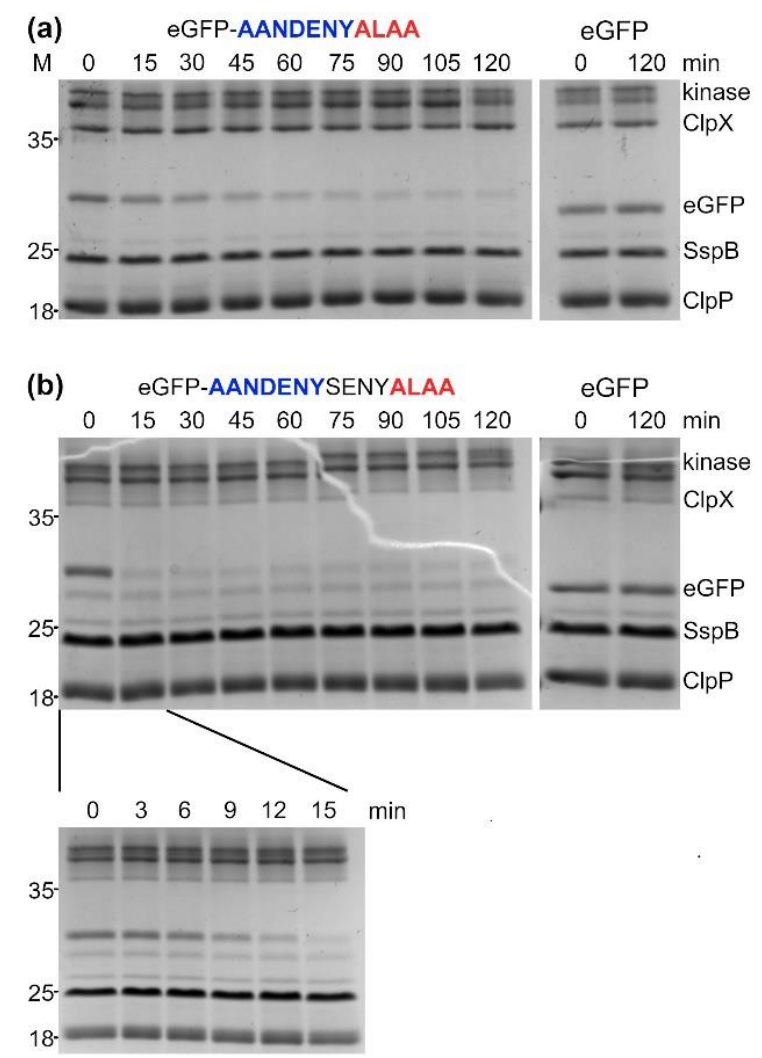

Figure 5. SDS-PAGE analysis of the in vitro eGFP-degron degradation by ClpXP. The progress of eGFP-AANDENYALAA (a) and eGFP-AANDENYSENYALAA (b) degradation in the presence of $2.5 \mu \mathrm{M} \mathrm{SspB} 2$ protein was sampled over a time course of $2 \mathrm{~h}$. Degradation of eGFP without a degron tag served as a control (right).

\subsection{In Vivo Degradation of eGFP-Degrons}

Our results of the in vitro degradation assays obtained for eGFP-degrons were confirmed by additional in vivo analyses carried out in bacterial cultures. Two methods were used: an analysis of changes in eGFP-degron fluorescence either in liquid culture over time (Figure 6a) or in a spot assay on agar plates (Figure 6b). The favored method of comparing degron efficiency was an estimation of the level of eGFP fluorescence of bacterial colonies overexpressing eGFP-degrons in the plate spot assay (Figure 6b). The fluorescence level of eGFP-degrons was determined for WT strain and three mutant strains $\Delta c l p X, \Delta c l p P$ and $\Delta s s p B$ to establish whether $\mathrm{ClpX}, \mathrm{ClpP}$ or SspB would affect degradation. In the WT strain eGFP-degron degradation resulted in the fastest and largest decrease in fluorescence for AANDENYALAA, ALAA, SENYALAA, and AANDENYSENYALAA degrons (Figure 6a,c). A slower decrease was observed for AANDENYAANDENY, AANDENYSENYADAS, and for the more lagging AANDENYADAS (Figure 6a), correlating also with the lower fluorescence level in the spot assay for these three degrons (Figure $6 \mathrm{~b}$ ). AANDENY, AANDENYSENY, ADAS, and SENYADAS degrons resulted in only slight decrease in fluorescence, with AANDENY matching the most closely the levels of eGFP without any degron tag (Figure $6 \mathrm{a}, \mathrm{c})$. The overall trends in fluorescence levels were similar in the WT, $\Delta c l p X$ and $\Delta s s p B$ strains (Figure $6 \mathrm{c}, \mathrm{d}, \mathrm{f}$ ), with ALAA-containing degrons causing the most efficient eGFP degradation, and this reduction was the most evident in the $\triangle s s p B$ strain. For the $\triangle c l p P$ strain, substantial degradation was observed only for the eGFP-ALAA fusion (Figure $6 \mathrm{~b}, \mathrm{e}$ ). 
(a)

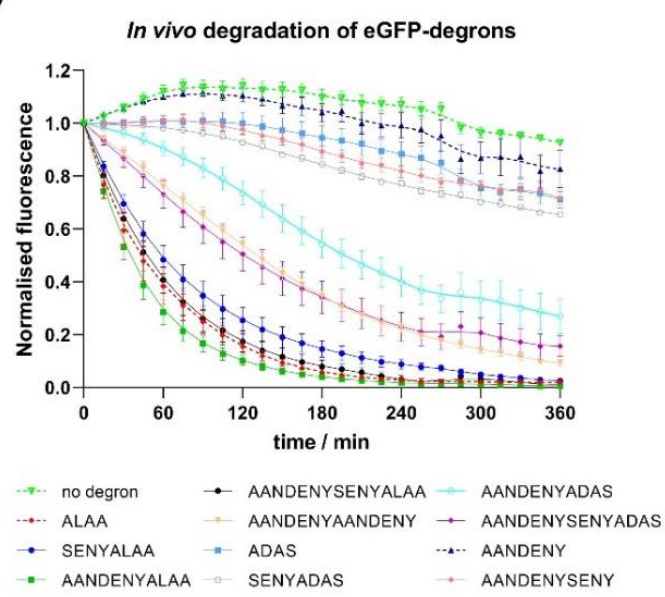

(c)

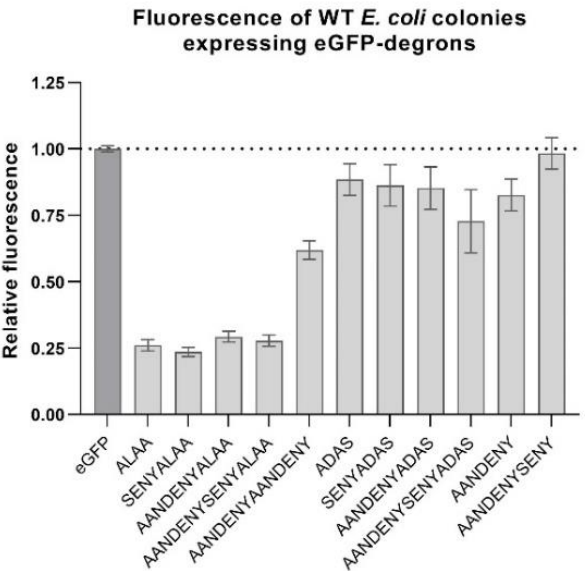

(b)

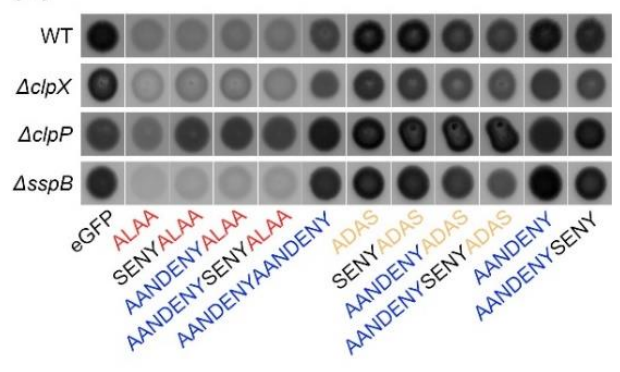

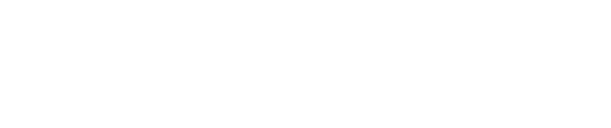




\section{Discussion}

For the purpose of comparing and characterizing the properties of ssrA variants, it was necessary to set up expression and purification protocols for all the eGFP-degrons and the components of the ClpX-ClpP-SspB complex, as well as methods required to check their activity and interactions. The expression of proteins at the beginning in Top10 for eGFP-degrons and in BL21 (DE3) for ClpX, ClpP and SspB unfortunately resulted in a noticeable degradation of eGFP-degrons and ClpX. Difficulties in ClpX expression, which in our hands was generally the most challenging protein to purify, could be attributed to the high mobility of the ZBD domain, which can be easily digested by various proteases. Similar problems were encountered previously in structural studies of ClpX. Typically, ClpX structures were obtained without the ZBD domain [25], and if ZBD was present, the resolution for ZBD was much lower than for the rest of the ClpX structure [26]. For eGFPdegrons the observed degradation likely took place during their expression in bacteria, as might be expected for efficiently working degradation signals. Only by switching to expression in the $\triangle c l p P$ strain could we obtain proteins that did not show significant degradation.

In the next step we ascertained that $\mathrm{ClpX}$ was active in an ATPase assay. Our results confirmed the previously reported $[27,28]$ positive effect of the SspB adaptor on the ATPase activity of ClpX. Since ZBD is explicitly necessary for the interaction with SspB [29], this strongly indicated the presence of a functional ZBD domain within the ClpX protein, with the downstream consequences on degradation by improving substrate engagement by ClpX.

The analysis of binding of eGFP-degrons to SspB protein studied on native gels confirmed the previously reported results of a mutational analysis of the GFP-ssrA tag [30] that AANDENY sequence was necessary for the eGFP-degrons to bind SspB. Our MST measurements allowed for a more detailed binding analysis and the determination of the $\mathrm{K}_{\mathrm{D}}$ for eGFP-ssrA and SspB at $\sim 80 \mathrm{nM}$. Similar $\mathrm{K}_{\mathrm{D}}$ values were observed previously in ITC measurements for GFP-ssrA and SspB, where the binding constant was determined to be $75 \pm 30 \mathrm{nM}$ [22] or even $16 \pm 4 \mathrm{nM}$ [27]. The application of the eGFP-degron fusions allowed us not only to evaluate the interactions using MST but also to reduce the $\mathrm{K}_{\mathrm{D}}$ value by one order of magnitude compared to the isolated ssrA tag, which is known to bind SspB more weakly [27]. Additionally, MST is a relatively high-throughput and precise method that allowed us to determine even minor differences in the binding of the SspB protein to the eGFP-degrons. We noted that the ADAS sequence caused a slight decrease in the eGFP-degron binding to SspB in contrast to the WT ALAA end, despite the expected independence of the AANDENY and ALAA modules in binding to SspB and ClpX, respectively. This difference may be due to steric requirements or electrostatic interactions related to the presence of the negatively charged aspartate in the DAS fragment. To our knowledge, this is the first time that the DAS fragment has been reported to negatively influence SspB binding since, typically, the C-terminal amino acids of ssrA have been tested mostly for recognition by ClpX [20]. It is not clear whether the disruptive effect of DAS would have any physiological relevance since it was observed under isolated conditions. However it could be of importance in the design of AANDENY-containing modules used to mediate interactions with the SspB protein. Our results suggest that the sequence that follows the AANDENY fragment should also meet specific requirements for the most efficient binding of the substrate protein by SspB. Overall degron length did not matter in SspB binding, even in the case of the eGFP-AANDENYAANDENY variant which seemed to bind better to SspB but without a significant change of the $K_{D}$. This may suggest the impossibility of $\mathrm{SspB}$ occupying more than one binding site on such a short peptide regardless of the presence of two SspB binding sites. This result may also indicate relatively slow dissociation of the complex between SspB and the AANDENY motif, which would render the second binding motif present in AANDENYAANDENY less relevant for improving SspB binding despite the increased local concentration of binding sites. 
The key part of our work was comparing the degradation effectiveness of eGFPdegrons by the ClpXP complex and the effect of SspB on it. The application of our standardized reaction conditions throughout our assays to a whole set of ssrA tag variants made it easier to compare their $\mathrm{K}_{\mathrm{M}}$ values and draw conclusions which parts of degrons are necessary for degradation, which can be replaced, and which are largely negligible. In the absence of SspB, degradation was observed only for eGFP-degrons containing the ALAA end preceded with an extending fragment such as the SENY linker. The longer the preceding fragment, the more efficient the degradation was observed. The ALAA fragment alone was insufficient for degradation. The ADAS fragment which is known to interact weaker with ClpX [20], rendered eGFP fusions retardant to degradation regardless of the extension preceding ADAS, even for the longest AANDENYSENYADAS degron variant.

In the presence of $S s p B$ the $K_{M}$ values for eGFP-degrons which were degraded without $\mathrm{SspB}$ were further lowered. Additionally, degradation was induced for 3 more eGFPdegrons (AANDENYADAS, AANDENYSENYADAS, AANDENYAANDENY), proving the positive influence of the AANDENY motif on the degradation efficiency and even compensating for the weaker binding of the mutated ADAS equivalent of ALAA. eGFPAANDENYAANDENY was degraded efficiently despite the lack of the ClpX binding motif (ALAA or ADAS), suggesting that the terminal repeat of the AANDENY fragment provided sufficient reach to bind nonspecifically to ClpX pore entrance for degradation. The decrease in $\mathrm{K}_{\mathrm{M}}$ was also observed for the eGFP-SENYALAA, which does not have the AANDENY motif and did not bind to SspB. This improvement in degradation efficiency could be attributed to the increased ClpX activity in the presence of SspB, as observed in our ATPase activity assays. Such a boost could result in the increased degradation of eGFP-SENYALAA by ClpX without direct SspB binding to the degron. However, the increased ATPase activity was not sufficient to efficiently degrade short degrons or degrons lacking the ALAA fragment. In summary, the eGFP-degron must be able to engage ClpX and be at least slightly degradable in the absence of SspB for SspB to positively influence its degradation through stimulation of ClpX ATPase activity. The positive effect of SspB on degradation efficiency was consistent with the literature data $[20,21,27]$. The slight differences in the intensity of its effect may be attributed to the differences in the experimental conditions. Despite these differences, our results and the literature data both indicated [21] that the highest impact of SspB on the eGFP-degron degradation efficiency was observed for the eGFP-AANDENYSENYADAS variant.

The results obtained in vivo were consistent with our in vitro results showing that eGFP-degrons containing the ALAA sequence were degraded the most efficiently. Significantly reduced fluorescence was observed for those variants (AANDENYALAA, AANDENYSENYALAA and SENYALAA), for which eGFP-degrons were also degraded in vitro even in the absence of SspB. For the remaining eGFP-degrons, the decrease of fluorescence was not pronounced, confirming again in vitro degradation requirements for the proper degron length and the ALAA fragment. An additional common element for our in vitro and in vivo results was the atypical behavior of the eGFP-ALAA fusion, which was degraded in vitro with an intermediate efficiency among our set of degrons even in the absence of SspB, but with a linear dependence on the tested substrate concentration that prevented determination of $K_{M}$ values. eGFP-ALAA was degraded very efficiently in vivo independently of all the factors we addressed. This was not due to the low level of eGFPALAA expression which was deemed sufficiently high by our time-course experiments, but rather that it could be degraded by other proteases outside the ClpXP pathway. This could result from a cross-talk of the ssrA system with other pathways in which hydrophobic or alanine-rich degrons are recognized as signals for degradation. The involvement of other proteases is likely if we take into account that in the $\Delta c l p X$ strain some eGFP-degrons were still degraded, whereas in the $\triangle c l p P$ strain only the aforementioned eGFP-ALAA was depleted. Our results indicate that in BW25113 cells, ClpX is redundant for ssrA-tagged substrates and could be successfully replaced by another unfoldase such as ClpA [7,18]. Degradation observed in the $\Delta s s p B$ strain was similar to that observed for WT and $\Delta c l p X$ 
strains, corroborating the redundancy of the ClpX pathway or the SspB itself. Recently, it was shown that the E. coli ribosome-associated trigger factor (TF), a chaperonin which is highly abundant in the cell and acts early during the folding process, enhances degradation of various ClpXP complex substrates including ssrA-tagged proteins both in vitro and in vivo [31]. The role of TF as an additional adaptor could contribute to the lack of an effect of $s s p B$ deletion on our tested eGFP-degrons.

The results and protocols presented here can serve as a benchmark for designing new degrons as well as providing guidelines on their comparison. However, the degron research strategies we used also have their limitations. Firstly, the complicated stoichiometry of oligomeric components may pose a problem. Changes in stoichiometry can cause changes in degradation kinetics (especially if the substrate is also an oligomer) or in the selectivity of the degradation system. Secondly, it is crucially important to test degron performance in the case of individual substrates/targeted proteins, as the substrate itself may alter degron availability and thus affect the efficiency of degron binding or its degradation. With these difficulties in mind, we aimed at establishing the most robust and straightforward strategies and methods, which allowed us to discover subtle differences between degrons in terms of their binding strength or degradation efficiency.

Building on this type of knowledge, degron variants can be fine-tuned for two basic types of applications. We ranked the propensity of the tested ssrA variants for SspB binding and for eGFP-degron degradation (Figure 7), which should facilitate the choice of the degron appropriate to the desired task. If efficient degradation of the fusion protein is desired, the best binding to SspB is provided by the WT ssrA sequence, but in the absence of SspB, AANDENYSENYALAA would be an even better choice. Our results confirm that AANDENYSENYADAS and AANDENYADAS enable degradation which might be regulated by SspB presence [32-34]. The SsrA degron is often used simply as an interaction module, for example in photoswitches [35]. In this case, if only promoted interaction with $\mathrm{SspB}$ is desired, then AANDENY or AANDENYSENY degrons would be the most suitable choice for efficient tag binding without degradation.

Degrons can also be exploited as protease recruiting ligands in the design of degrader molecules in the targeted protein degradation field [14]. For this purpose, it is essential to distinguish the effects of degron sequence and length on adaptor and protease binding from those parameters that lead to degradation and depletion of the degron-based molecular tools. Our benchmark of methods and protocols may serve the budding targeted protein degradation studies in bacteria in establishing more stable and efficient bacterial degraders.

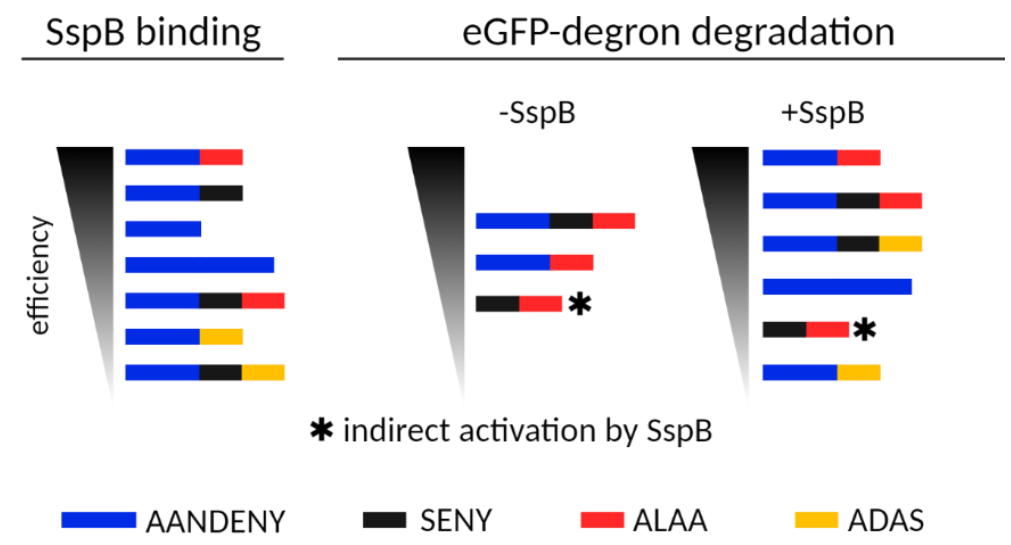

Figure 7. A schematic representation of eGFP-degron properties as ranked by their SspB binding efficiency and eGFP-degron degradation. 


\section{Materials and Methods}

4.1. Cloning of clpP, clpX and sspB Genes to $p E T 28$ a Expression Vector by Sequence and Ligation Independent Cloning (SLIC)

DNA encoding full-length $c l p P, c l p X$ and $s s p B$ genes of Escherichia coli (Top10 strain) was obtained by colony PCR amplification using specific primers (Supplementary Materials, Table S1) containing sequences complementary to pET28a plasmid with His tag and SUMO protease cleavage site.

The SLIC reaction was performed by mixing $100 \mathrm{ng}$ of pET28a linearized empty vector, $100 \mathrm{ng}$ of PCR-amplified DNA fragment (with $\operatorname{clpP}, \operatorname{clpX}$ or $\operatorname{ssp} B$ gene) and $1 \mathrm{U}$ of T4 DNA polymerase (Thermo Fisher Scientific, Waltham, MA, USA) in 1X FastDigest Green Buffer (Thermo Fisher Scientific, Waltham, MA, USA) in a volume of $30 \mu \mathrm{L}$. After 30 min incubation in RT, reactions were stopped by adding dCTP (EURx, Poland) to a final concentration of $1 \mathrm{mM}$, and the tubes were incubated for $30 \mathrm{~min}$ at $37^{\circ} \mathrm{C}$ for annealing. Finally, reactions were transformed to $E$. coli Top10 for selection on kanamycin.

For the preparation of pBAD-eGFP-degron constructs (Supplementary Materials, Table S2), we modified eGFP-pBAD plasmid (later referred to as pBAD-eGFP) containing His-TEV-tagged eGFP gene, obtained from Michael Davidson (Addgene plasmid \# 54762; http:/ /n2t.net/addgene:54762 (accessed on 26 July 2021); RRID:Addgene_54762). The C-terminal degrons were appended to the eGFP gene by site-directed mutagenesis. Primers used for PCR (Supplementary Materials, Table S1) were designed to amplify an entire pBAD-eGFP plasmid while simultaneously adding degrons. The PCR products were then ligated and phosphorylated, and the obtained constructs were transformed into E. coli Top10 for selection on ampicillin.

Successfully transformed bacteria were used for plasmid isolation, and all constructs were verified by sequencing. The sequences of $\operatorname{clp} P, \operatorname{clpX}$ and $s s p B$ were identical to the corresponding genes from strain K-12 substrain MG1655 which is widely used as a model E. coli strain (GenBank: U00096.3).

\subsection{Protein Expression and Purification}

For in vitro studies protein expression was carried out in BL21 DE3 bacteria (for ClpX, ClpP, SspB), in E. coli Top10 strain (for eGFP-degrons) and in $\Delta c l p P$ Keio collection strain [36] (JW0427) (for ClpX, eGFP-degrons) using LB media with induction at $\mathrm{OD}_{600}$ 0.5 with $0.5 \mathrm{mM}$ IPTG for pET28a constructs in BL21 DE3 strain or $0.02 \%$ arabinose (VWR International, USA) for pBAD constructs in Top10 and $\triangle c l p P$ strains. Overexpression of $\mathrm{ClpP}$, SspB and eGFP-degrons was carried out at $30^{\circ} \mathrm{C}$ for $3 \mathrm{~h}, \mathrm{ClpX}$ at $18{ }^{\circ} \mathrm{C}$ overnight, all at $140 \mathrm{rpm}$. Bacterial pellet was collected by centrifugation $(5000 \mathrm{rpm}[5180 \times g], 30 \mathrm{~min}$, at $4{ }^{\circ} \mathrm{C}$ ) and frozen at $-20^{\circ} \mathrm{C}$ for later use.

ClpX, ClpP, SspB and eGFP-degrons were purified on HisTrap HP $5 \mathrm{~mL}$ column (GE Healthcare, North Richland Hills, TX, USA) following the manufacturer's guidelines. The lysis/loading buffer contained $50 \mathrm{mM}$ Tris pH 8.0, $20 \mathrm{mM}$ imidazole, $500 \mathrm{mM} \mathrm{NaCl}$ (for ClpX and eGFP-degrons) or alternatively $1 \mathrm{M} \mathrm{NaCl}$ (for ClpP and SspB) and with addition of $1 \mathrm{mM}$ DTT for ClpX. Lysis by incubation for $30 \mathrm{~min}$ (on a rotator at $4{ }^{\circ} \mathrm{C}$ ) with lysozyme (100 mg) and DNase (20 U) was followed by sonication (15 min, $45 \mathrm{on} / 15 \mathrm{off} \mathrm{s}$, $40 \%$ amplitude at $4{ }^{\circ} \mathrm{C}$ ) (Sonics \& Materials Inc., Newtown, CT, USA) and centrifugation $\left(20,000 \mathrm{rpm}[48,380 \times \mathrm{g}], 30 \mathrm{~min}, 4^{\circ} \mathrm{C}\right)$. Lysates were cleared by filtration $(0.45 \mu \mathrm{m})$ and applied on the HisTrap column. ClpX, ClpP and SspB elutions (using lysis/loading buffer supplemented to $1 \mathrm{M}$ imidazole) were visualized on SDS-PAGE (Bio-Rad Laboratories, Hercules, CA, USA) and proper fractions were selected, then combined and treated with SUMO protease for His-SUMO tag removal ( $2 \mathrm{~h}$ on a rotator at $\left.4{ }^{\circ} \mathrm{C}\right)$. After cleavage, samples were concentrated in 10K MWCO centricons (Pall Corporation, Washington, DC, USA) (5000 rpm [3214 $\times \mathrm{g}]$ at $\left.4{ }^{\circ} \mathrm{C}\right)$ and applied on a Superdex200 HiLoad $16 / 600$ column (GE Healthcare, North Richland Hills, TX, USA) using 25 mM Hepes pH 7.6, 200 mM $\mathrm{KCl}, 5 \mathrm{mM} \mathrm{MgCl} 2,10 \%$ glycerol buffer with the addition of $0.5 \mathrm{mM}$ of TCEP in case of ClpX. The eGFP-degrons were purified on HisTrap and Superdex200 columns in a tandem 
configuration without purification tag (His-TEV) removal in between. Based on SDSPAGE, selected SEC fractions were combined, and protein concentration was measured using the Bradford method (for ClpX) (Tecan, Männedorf, Switzerland) or based on the UV absorbance profile (for ClpP, SspB, His-TEV-eGFP-degrons, further denoted as eGFPdegrons) (DeNovix Inc., Wilmington, NC, USA). All proteins were flash frozen in liquid nitrogen and stored at $-80^{\circ} \mathrm{C}$ for later experiments.

\subsection{ATP Activity Assay}

In vitro ATP hydrolysis by $\mathrm{ClpX}$ was measured using an NADH-coupled assay as previously described [37]. A mixture of ClpX interacting protein (0-27.4 $\mu \mathrm{M} \mathrm{SspB}_{2}$, eGFPSsrA or eGFP-SsrA with constant concentration of $\left.2.5 \mu \mathrm{M} \mathrm{SspB}_{2}\right), 2.5 \mathrm{mM}$ ATP, $2.5 \mathrm{mM}$ phosphoenolpyruvate, $50 \mu \mathrm{g} / \mathrm{mL}$ pyruvate kinase, $1 \mathrm{mM} \mathrm{NADH}$, and $50 \mu \mathrm{g} / \mathrm{mL}$ lactate dehydrogenase (Merck, Darmstadt, Germany) in the reaction buffer $(50 \mathrm{mM}$ Tris- $\mathrm{HCl}$ $\mathrm{pH} 7.5,200 \mathrm{mM} \mathrm{NaCl}, 5 \mathrm{mM} \mathrm{MgCl} 2$ ) was incubated at $30^{\circ} \mathrm{C}$ for $30 \mathrm{~min}$. As a negative control for the study of the eGFP-ssrA interaction, an eGFP protein not fused to ssrA degron was used. The assay was started by the addition of $\mathrm{ClpX}_{6}$ to a final concentration of $0.08 \mu \mathrm{M}$ in the $100 \mu \mathrm{L}$ final reaction volume. Changes in NADH concentration were monitored by measuring absorbance at $340 \mathrm{~nm}$ for $1.5 \mathrm{~h}$ (in $1 \mathrm{~min}$ intervals) at $30{ }^{\circ} \mathrm{C}$ in a 96 well plate (Greiner Bio-One, Kremsmünster, Austria) in a Tecan Infinite M200 Pro plate reader instrument (Tecan, Männedorf, Switzerland). All measurements were performed at least in a triplicate. The rate of ADP formation was calculated from the linear loss of fluorescence assuming a 1:1 correspondence between ATP regeneration and NADH oxidation and a $\Delta \varepsilon_{340}$ of $6.23 \mu \mathrm{M}^{-1} \mathrm{~cm}^{-1}$. Curve fitting and statistical analysis was performed via Graphpad Prism 9 software (Graphpad Software, LLC, San Diego, CA, USA).

\subsection{Native Electrophoresis}

In vitro protein-protein interaction studies were performed by means of non-denaturing polyacrylamide gel electrophoresis. Individual proteins $(8 \mu \mathrm{M}$ for eGFP-degron and $8 \mu \mathrm{M}$ for $\left.\mathrm{SspB}_{2}\right)$ or protein mixtures $(8 \mu \mathrm{M}$ each) were incubated prior to electrophoresis for approximately $10 \mathrm{~min}$ at RT in the reaction buffer $(50 \mathrm{mM}$ Tris- $\mathrm{HCl} \mathrm{pH} \mathrm{7.5,} 200 \mathrm{mM} \mathrm{NaCl}$, $5 \mathrm{mM} \mathrm{MgCl} 2$ ). Protein samples were separated on $15 \%$ native polyacrylamide gels in Tris/borate buffer and the results visualized by staining the gels with SimplyBlue Safe Stain (Invitrogen, LC6060, Thermo Fisher Scientific).

\subsection{Microscale Thermophoresis (MST)}

For measurements of binding between SspB and eGFP-degrons, $100 \mathrm{nM}$ eGFP-degrons and a series of 16 two-fold dilutions of SspB ranging from $7.45 \mathrm{nM}$ to $244 \mu \mathrm{M}$ in MST buffer ( $25 \mathrm{mM}$ Hepes pH 7.6, $200 \mathrm{mM} \mathrm{KCl}, 5 \mathrm{mM} \mathrm{MgCl}_{2}, 10 \%$ glycerol) supplemented with $0.05 \%$ Tween 20 were prepared. Then each ligand dilution was mixed with one volume of eGFP-degron, which led to the final eGFP-degron concentration of $50 \mathrm{nM}$ and final SspB concentrations ranging from $3.72 \mathrm{nM}$ to $122 \mu \mathrm{M}$. After 15 min incubation at RT, the samples were loaded into Monolith NT.115 Premium Capillaries (NanoTemper Technologies, München, Germany), and measurements were carried out using the Monolith NT.115 instrument (NanoTemper Technologies, München, Germany) at $20^{\circ} \mathrm{C}$. Instrument parameters were adjusted to $20 \%$ LED power and medium MST power.

All measurements were performed at least in triplicates. Protein binding parameters were calculated using the signal from an MST-on time of $10 \mathrm{~s}$. Curve fitting and Scatchard plots, and statistical analysis of the obtained constants were performed via Graphpad Prism 9 software (Graphpad Software, LLC, San Diego, CA, USA).

\subsection{Fluorescence-Based Measurements of In Vitro Degradation}

In vitro degradation of eGFP-degron by ClpXP analysis was performed in the $100 \mu \mathrm{L}$ final volume in the reaction buffer ( $50 \mathrm{mM}$ Tris- $\mathrm{HCl} \mathrm{pH} \mathrm{7.5,} 200 \mathrm{mM} \mathrm{NaCl}, 5 \mathrm{mM} \mathrm{MgCl}$ ). 
A mixture of $0.08 \mu \mathrm{M} \mathrm{ClpX}_{6}$, eGFP-degron $(0-10 \mu \mathrm{M})$, SspB (2.5 $\mu \mathrm{M} \mathrm{SspB}{ }_{2}$, if added), $4 \mathrm{mM}$ ATP, $2.5 \mathrm{mM}$ creatine phosphate, and $50 \mu \mathrm{g} / \mathrm{mL}$ creatine kinase was incubated at $30{ }^{\circ} \mathrm{C}$ for $30 \mathrm{~min}$. As a negative control, the eGFP protein not fused with any degron was used. The degradation assay was started by the addition of $0.21 \mu \mathrm{M} \mathrm{ClpP} 14$ for the final protease machinery assembly in $\mathrm{ClpX}_{6}: \mathrm{ClpP}_{14}=3: 8$ ratio. Changes in eGFP fluorescence (at excitation $\lambda=489 \mathrm{~nm}$ and emission $\lambda=550 \mathrm{~nm}$ ) were monitored for $1.5 \mathrm{~h}$ at $30^{\circ} \mathrm{C}$ in a Tecan Infinite M200 Pro plate reader instrument. All measurements were performed at least in triplicates. Degradation rates were calculated from the initial linear loss of eGFP fluorescence. Curve fitting using the Michaelis-Menten equation and statistical analysis was performed via Graphpad Prism 9 software (Graphpad Software, LLC, San Diego, CA, USA).

\subsection{SDS-PAGE Analysis of In Vitro Degradation}

Reactions for SDS-PAGE analysis of in vitro eGFP-degron degradation by ClpXP were prepared the same way as for fluorescence readouts, with eGFP-degron or eGFP concentration set at $1 \mu \mathrm{M}$. $10 \mu \mathrm{L}$ samples were collected in 15 min intervals up to $120 \mathrm{~min}$ (with additional time points for AANDENYSENYALAA of 3, 6, 9 and $12 \mathrm{~min}$ ). The reaction was stopped by adding the SDS-PAGE loading buffer followed by 5 min incubation at $95^{\circ} \mathrm{C}$. Prepared samples were applied on $12 \%$ SDS-PAGE gels, which were developed at 200 V. Resolved proteins were visualized using the SafeStain method.

\subsection{Time-Course Measurements of In Vivo Degradation}

Precultures were prepared by inoculating a small amount of a glycerol stock of E. coli BW25113 (previously transformed with pBAD-eGFP constructs) in liquid LB medium with ampicillin $(50 \mu \mathrm{g} / \mathrm{mL})$ and incubating overnight at $37^{\circ} \mathrm{C}$ in an orbital shaker. The following day, the precultures were diluted 50 times in fresh medium and the cultures were grown to mid-exponential phase. The expression of eGFP-degron fusions was induced by addition of L-arabinose to the final concentration of $0.001 \%$. The induced cultures were incubated overnight in $18{ }^{\circ} \mathrm{C}$. Bacteria were then diluted 10 times by adding $20 \mu \mathrm{L}$ of the cultures to $180 \mu \mathrm{L}$ of $\mathrm{M} 9$ medium supplemented with glucose $(5 \%)$, thiamine $(10 \mu \mathrm{g} / \mathrm{mL})$, biotin $(10 \mu \mathrm{g} / \mathrm{mL})$, trace elements, and additionally spectinomycin $(100 \mu \mathrm{g} / \mathrm{mL})$ to stop protein translation. The measurements of $\mathrm{OD}_{600}$ and fluorescence (excitation at $\lambda=489 \mathrm{~nm}$ and emission at $\lambda=520 \mathrm{~nm}$ ) were made every $15 \mathrm{~min}$ for $6 \mathrm{~h}$ using Tecan Infinite M200 Pro plate reader (Tecan, Männedorf, Switzerland) at $30^{\circ} \mathrm{C}$. The fluorescence results were normalized to the optical density. The measurements were further normalized by setting the values at zero time points as $100 \%$.

\subsection{Plate Spot Assay of In Vivo Degradation}

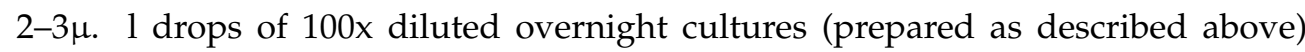
were placed in triplicates or quadruplicates on LB agar plates supplemented with $0.001 \%$ L-arabinose and antibiotics: ampicillin $(50 \mu \mathrm{g} / \mathrm{mL})$ for WT strain (BW25113), and ampicillin $(50 \mu \mathrm{g} / \mathrm{mL})$ with kanamycin $(15 \mu \mathrm{g} / \mathrm{mL})$ for the deletant strains $(\Delta c l p X$ (JW0428-KC), $\triangle c l p P(\mathrm{JW} 0427-\mathrm{KC})$ and $\Delta s s p B(\mathrm{JW} 0866-\mathrm{KC})$ ). The plates were incubated overnight at $37^{\circ} \mathrm{C}$. Images of the plates were taken with the Bio-Rad Chemidoc Imager (Bio-Rad, Philadelphia, PA, USA) using a fluorescein filter and analyzed with Fiji software [38].

Supplementary Materials: The following are available online. Supplementary Table S1: Sequences of the vectors used in the experiments, Supplementary Table S2: List of primers used for cloning the protease complex components and site-directed mutagenesis for preparing pBAD-eGFP-degron constructs, Supplementary Figure S1: SDS-PAGE gel with fractions collected after tandem purification of HisTEV-eGFP-AANDENYSENY expressed in E. coli Top10, Supplementary Figure S2: MST results for the binding of eGFP-degrons containing the AANDENY motif to SspB.

Author Contributions: A.A. and M.A.I. contributed equally to this work. Conceptualization, M.M.K., A.A., M.A.I., P.E.S. and M.W.G.; methodology, M.M.K., A.A., M.A.I., P.E.S., P.K.T., C.D. and M.W.G.; 
validation, M.M.K., A.A., M.A.I., P.E.S. and P.K.T.; statistical analysis, A.A.; investigation, M.M.K., A.A., M.A.I., P.E.S., P.K.T. and C.D.; writing-original draft preparation, M.M.K., A.A., M.A.I., P.E.S. and M.W.G.; writing-review and editing, M.M.K., A.A., M.A.I. and M.W.G.; visualization, M.M.K., M.A.I., A.A. and M.W.G.; supervision, M.M.K., A.A., M.A.I. and M.W.G.; project administration, M.M.K. and M.W.G.; funding acquisition, M.W.G. All authors have read and agreed to the published version of the manuscript.

Funding: This research was funded by grant number POIR.04.04.00-00-5EC1/18-00 for the project "Proteolysis-targeting strategies in bacterial systems for functional studies of proteins and improvement of antibiotics" carried out within the FIRST TEAM programme of the Foundation for Polish Science co-financed by the European Union under the European Regional Development Fund. Work in the laboratory was supported by the EMBO Installation grant to M.W.G. M.W.G. is the recipient of the L'Oréal-UNESCO For Women in Science scholarship from L'Oréal Poland and the Ministry of Education and Science, Poland.

Acknowledgments: We would like to thank Rafał Augustyniak for helpful discussions and Matthew Merski for help with editing and checking the manuscript.

Conflicts of Interest: The authors declare no conflict of interest.

\section{References}

1. Schrader, E.K.; Harstad, K.G.; Matouschek, A. Targeting proteins for degradation. Nat. Chem. Biol. 2009, 5, 815-822. [CrossRef]

2. Schramm, F.D.; Schroeder, K.; Jonas, K. Protein aggregation in bacteria. FEMS Microbiol. Rev. 2019, 44, 54-72. [CrossRef]

3. Mogk, A.; Huber, D.; Bukau, B. Integrating protein homeostasis strategies in prokaryotes. Cold Spring Harb. Perspect. Biol. 2011, 3, 1-19. [CrossRef]

4. Sauer, R.T.; Baker, T.A. AAA+ Proteases: ATP-Fueled Machines of Protein Destruction. Annu. Rev. Biochem. 2011, 80, 587-612 [CrossRef]

5. Neuwald, A.F.; Aravind, L.; Spouge, J.L.; Koonin, E.V. AAA+: A class of chaperone-like ATPases associated with the assembly, operation, and disassembly of protein complexes. Genome Res. 1999, 9, 27-43. [CrossRef]

6. Varshavsky, A. N-degron and C-degron pathways of protein degradation. Proc. Natl. Acad. Sci. USA 2019, 116, 358-366. [CrossRef]

7. Gottesman, S.; Roche, E.; Zhou, Y.N.; Sauer, R.T. The ClpXP and ClpAP proteases degrade proteins with carboxy-terminal peptide tails added by the SsrA-tagging system. Genes Dev. 1998, 12, 1338-1347. [CrossRef]

8. Buczek, M.S.; Arevalo, A.L.C.; Janakiraman, A. ClpXP and ClpAP control the escherichia coli division protein ZapC by proteolysis. Microbiology 2016, 162, 909-920. [CrossRef]

9. Ogle, C.T.; Mather, W.H. Proteolytic crosstalk in multi-protease networks. Phys. Biol. 2016, 13, 25002. [CrossRef]

10. Joshi, K.K.; Bergé, M.; Radhakrishnan, S.K.; Viollier, P.H.; Chien, P. An Adaptor Hierarchy Regulates Proteolysis during a Bacterial Cell Cycle. Cell 2015, 163, 419-431. [CrossRef]

11. Kuhlmann, N.J.; Chien, P. Selective adaptor dependent protein degradation in bacteria. Curr. Opin. Microbiol. 2017, 36, 118-127. [CrossRef]

12. Röth, S.; Fulcher, L.J.; Sapkota, G.P. Advances in targeted degradation of endogenous proteins. Cell. Mol. Life Sci. 2019, 76, 2761-2777. [CrossRef]

13. Prozzillo, Y.; Fattorini, G.; Santopietro, M.V.; Suglia, L.; Ruggiero, A.; Ferreri, D.; Messina, G. Targeted Protein Degradation Tools: Overview and Future Perspectives. Biology 2020, 9, 421. [CrossRef]

14. Izert, M.A.; Klimecka, M.M.; Górna, M.W. Applications of Bacterial Degrons and Degraders-Toward Targeted Protein Degradation in Bacteria. Front. Mol. Biosci. 2021, 8, 348. [CrossRef]

15. Fritze, J.; Zhang, M.; Luo, Q.; Lu, X. An overview of the bacterial SsrA system modulating intracellular protein levels and activities. Appl. Microbiol. Biotechnol. 2020, 104, 5229-5241. [CrossRef]

16. Keiler, K.C. Biology of trans -Translation. Annu. Rev. Microbiol. 2008, 62, 133-151. [CrossRef]

17. Dougan, D.A.; Reid, B.G.; Horwich, A.L.; Bukau, B. ClpS, a substrate modulator of the ClpAP machine. Mol. Cell 2002, 9, 673-683. [CrossRef]

18. Farrell, C.M.; Grossman, A.D.; Sauer, R.T. Cytoplasmic degradation of ssrA-tagged proteins. Mol. Microbiol. 2005, 57, 1750-1761. [CrossRef]

19. Baker, T.A.; Sauer, R.T. ClpXP, an ATP-powered unfolding and protein-degradation machine. Biochim. Biophys. Acta-Mol. Cell Res. 2012, 1823, 15-28. [CrossRef]

20. McGinness, K.E.; Baker, T.A.; Sauer, R.T. Engineering Controllable Protein Degradation. Mol. Cell 2006, 22, 701-707. [CrossRef]

21. McGinness, K.E.; Bolon, D.N.; Kaganovich, M.; Baker, T.A.; Sauer, R.T. Altered tethering of the SspB adaptor to the ClpXP protease causes changes in substrate delivery. J. Biol. Chem. 2007, 282, 11465-11473. [CrossRef]

22. Hersch, G.L.; Baker, T.A.; Sauer, R.T. SspB delivery of substrates for ClpXP proteolysis probed by the design of improved degradation tags. Proc. Natl. Acad. Sci. USA 2004, 101, 12136-12141. [CrossRef] [PubMed] 
23. Davis, J.H.; Baker, T.A.; Sauer, R.T. Engineering Synthetic Adaptors and Substrates for Controlled ClpXP Degradation. J. Biol. Chem. 2009, 284, 21848-21855. [CrossRef] [PubMed]

24. Sehnal, D.; Rose, A.S.; Koča, J.; Burley, S.K.; Velankar, S. Mol*: Towards a common library and tools for web molecular graphics. Work. Mol. Graph. Vis. Anal. Mol. Data 2018, 29-33. [CrossRef]

25. Fei, X.; Bell, T.A.; Barkow, S.R.; Baker, T.A.; Sauer, R.T. Structural basis of ClpXP recognition and unfolding of ssrA-tagged substrates. Elife 2020, 9. [CrossRef]

26. Gatsogiannis, C.; Balogh, D.; Merino, F.; Sieber, S.A.; Raunser, S. Cryo-EM structure of the ClpXP protein degradation machinery. Nat. Struct. Mol. Biol. 2019, 26, 946-954. [CrossRef] [PubMed]

27. Wah, D.A.; Levchenko, I.; Baker, T.A.; Sauer, R.T. Characterization of a Specificity Factor for an AAA+ ATPase. Chem. Biol. 2002, 9 , 1237-1245. [CrossRef]

28. Song, H.K.; Eck, M.J. Structural basis of degradation signal recognition by SspB, a specificity-enhancing factor for the ClpXP proteolytic machine. Mol. Cell 2003, 12, 75-86. [CrossRef]

29. Park, E.Y.; Lee, B.G.; Hong, S.B.; Kim, H.W.; Jeon, H.; Song, H.K. Structural Basis of SspB-tail Recognition by the Zinc Binding Domain of ClpX. J. Mol. Biol. 2007, 367, 514-526. [CrossRef]

30. Flynn, J.M.; Levchenko, I.; Seidel, M.; Wickner, S.H.; Sauer, R.T.; Baker, T.A. Overlapping recognition determinants within the ssrA degradation tag allow modulation of proteolysis. Proc. Natl. Acad. Sci. USA 2001, 98, 10584-10589. [CrossRef]

31. Rizzolo, K.; Yu, A.Y.H.; Ologbenla, A.; Kim, S.R.; Zhu, H.; Ishimori, K.; Thibault, G.; Leung, E.; Zhang, Y.W.; Teng, M.; et al. Functional cooperativity between the trigger factor chaperone and the ClpXP proteolytic complex. Nat. Commun. 2021, 12, 281. [CrossRef]

32. Griffith, K.L.; Grossman, A.D. Inducible protein degradation in Bacillus subtilis using heterologous peptide tags and adaptor proteins to target substrates to the protease ClpXP. Mol. Microbiol. 2008, 70, 1012-1025. [CrossRef]

33. Davis, J.H.; Baker, T.A.; Sauer, R.T. Small-molecule control of protein degradation using split adaptors. ACS Chem. Biol. 2011, 6 , 1205-1213. [CrossRef]

34. Kim, J.H.; Wei, J.R.; Wallach, J.B.; Robbins, R.S.; Rubin, E.J.; Schnappinger, D. Protein inactivation in mycobacteria by controlled proteolysis and its application to deplete the beta subunit of RNA polymerase. Nucleic Acids Res. 2011, 39, 2210-2220. [CrossRef] [PubMed]

35. Guntas, G.; Hallett, R.A.; Zimmerman, S.P.; Williams, T.; Yumerefendi, H.; Bear, J.E.; Kuhlman, B. Engineering an improved light-induced dimer (iLID) for controlling the localization and activity of signaling proteins. Proc. Natl. Acad. Sci. USA 2015, 112, 112-117. [CrossRef]

36. Baba, T.; Ara, T.; Hasegawa, M.; Takai, Y.; Okumura, Y.; Baba, M.; Datsenko, K.A.; Tomita, M.; Wanner, B.L.; Mori, H. Construction of Escherichia coli K-12 in-frame, single-gene knockout mutants: The Keio collection. Mol Syst Biol. 2006, 2, 2006-0008. [CrossRef] [PubMed]

37. Nørby, J.G. Coupled assay of Na+,K+-ATPase activity. Methods Enzymol. 1988, 156, 116-119. [CrossRef] [PubMed]

38. Schindelin, J.; Arganda-Carreras, E.; Frise, E.; Kaynig, V.; Longair, M.; Pietzsch, T.; Preibisch, S.; Rueden, C.; Saalfeld, S.; Schmid, B.; et al. Fiji: An open-source platform for biological-image analysis. Nat. Methods 2012, 9, 676-682. [CrossRef] [PubMed] 